\title{
Relación entre el rendimiento académico y la condición indígena de los estudiantes chilenos en pruebas estandarizadas
}

\author{
Esteban Saavedra Vallejos \\ Universidad Católica de Temuco. Chile. \\ esaavedra@educa.uct.cl
}

Recibido: $26 / 2 / 2020$

Aceptado: 5/5/2020

Publicado: 5/2/2021

\section{Resumen}

En dos regiones de Chile aproximadamente un tercio de la población es indígena y sus estudiantes se ven en problemas a la hora de aprender en las escuelas, debido a que no se contempla su idioma, su cosmovisión ni su episteme. Debido a esta circunstancia, se plantean tres objetivos específicos para evidenciar si existe una relación entre el porcentaje de estudiantes indígenas matriculados en un establecimiento educacional y el rendimiento promedio de las escuelas en las pruebas estandarizadas nacionales. El método empleado es cuantitativo ex post facto, con un diseño no experimental transeccional y correlacional. Los resultados muestran que existe una correlación negativa entre los resultados obtenidos en pruebas estandarizadas de matemáticas y lenguaje con el porcentaje de estudiantes indígenas de los establecimientos educacionales; el factor étnico explica un porcentaje del resultado en pruebas estandarizadas, y los establecimientos educacionales con baja proporción de estudiantes indígenas obtienen resultados significativamente más elevados en pruebas estandarizadas que los que cuentan con una alta proporción de estudiantes indígenas. En conclusión, los establecimientos educacionales que muestran una alta concentración de estudiantes indígenas obtienen resultados académicos más bajos que los que cuentan con una baja concentración de estudiantes indígenas en las dos macrozonas de Chile con mayor porcentaje de población indígena.

Palabras clave: evaluación; educación intercultural; rendimiento comparado; pluralismo cultural

Resum. Anàlisi correlacional de l'aplicabilitat de la classe inversa segons les particularitats de la pràctica docent

En dues regions de Xile aproximadament un terç de la població és indígena i els estudiants es troben amb problemes a l'hora d'aprendre a les escoles, perquè no se'n contempla l'idioma, la cosmovisió ni l'episteme. A causa d'aquesta circumstància es plantegen tres objectius específics per evidenciar si hi ha una relació entre el percentatge d'estudiants indígenes matriculats en un establiment educacional i el rendiment mitjà de les escoles en les proves estandarditzades nacionals. El mètode emprat és quantitatiu ex post facto, amb un disseny no experimental transeccional i correlacional. Els resultats mostren que hi ha una correlació negativa entre els resultats obtinguts en proves estandarditzades de matemàtiques i llenguatge amb el percentatge d'estudiants indígenes dels centres educacionals; el factor 
ètnic explica un percentatge del resultat en proves estandarditzades, i els centres educacionals amb baix percentatge d'estudiants indígenes obtenen resultats significativament més elevats en proves estandarditzades que no pas els que presenten un alt percentatge d'estudiants indígenes. En conclusió, els centres educacionals que tenen una alta concentració d'estudiants indígenes obtenen resultats acadèmics més baixos que els que mostren una baixa concentració d'estudiants indígenes en les dues macrozones de Xile amb un percentatge més elevat de població indígena.

Paraules clau: avaluació; educació intercultural; rendiment comparat; pluralisme cultural

\section{Abstract. Relationship between academic performance and the indigenous status of Chilean students in standardized tests}

In two regions of Chile approximately one third of the population is indigenous. In the schools of these regions, students of indigenous backgrounds experience learning difficulties because their language, worldview and episteme are not held in consideration. This article aims to empirically demonstrate whether there is a relationship between the percentage of indigenous students enrolled in an educational institution and the average performance of schools on national standardized tests. To this end, a quantitative ex post facto method with a non-experimental cross-sectional and correlational design was used. The results show that there is a negative correlation between the results in standardized mathematics and language tests and the percentage of indigenous students in educational institutions; the ethnic factor is a predictor that explains a small part of the results in standardized tests; and educational institutions with a low percentage of indigenous students have significantly higher results in standardized tests than those with a high percentage of indigenous students. In conclusion, schools with a high concentration of indigenous students achieve poorer academic results than those with fewer indigenous students in the two macro areas of Chile that have a large indigenous population.

Keywords: assessment; intercultural education; comparative performance; cultural diversity
Sumario
1. Introducción
6. Resultados
2. Método
7. Regresiones lineales
3. Contexto y muestra
8. Discusión y conclusión
4. Instrumento
Referencias bibliográficas

5. Análisis de datos

\section{Introducción}

La actual prueba estandarizada que mide los conocimientos y las habilidades de todos los estudiantes en Chile es el Sistema de Medición de la Calidad de la Educación (SIMCE), que ha evolucionado a partir de diferentes programas de medición de los aprendizajes. En 1982 se instaura la primera evaluación estandarizada nacional denominada Programa de Evaluación del Rendimiento Escolar (PER), que tres años más tarde es sustituida por el Sistema de 
Evaluación de la Calidad de la Educación (SEDE), que, al igual que la prueba PER, solo logra estar vigente tres años. En 1988 se crea el SIMCE, sistema de evaluación que se utiliza hasta la actualidad (Bravo, 2011). Esta evaluación se propone con la finalidad de «monitorear la efectividad del sistema y diseñar políticas pertinentes; evaluar la utilización de recursos y la aplicación de medidas; detectar sectores más débiles y diseñar estrategias correctivas» (Eyzaguirre y Fontaine, 1999, p. 109).

Al observar los objetivos y los fines del SIMCE (Bravo, 2011) se observa que es regido por un paradigma técnico, el que tiene por finalidad la medición de los objetivos presentes en el currículo (Tyler, 2013), en este caso, los planes y programas del currículo nacional de educación. Específicamente, se evalúan los objetivos de aprendizaje en comprensión de lectura y escritura, matemáticas, ciencias naturales, historia, geografía y ciencias sociales e inglés en niños que asisten a los cursos segundo, cuarto, sexto, octavo básico, y segundo y tercero de enseñanza media (MINEDUC, 2019).

En el año 2012, con el fin de mejorar los resultados de los estudiantes en las pruebas SIMCE, el Gobierno propone reformas educativas que estructuran el currículo nacional en base a objetivos de aprendizaje que puedan ser evaluados; aumenta el tiempo dedicado a matemáticas y lenguaje en 800 horas anuales, y disminuye horas de historia, música, artes y educación tecnológica (Pino, Oyarzún y Salinas, 2016). Desde estos planteamientos se observa que la preocupación de la normativa chilena no está alineada con la educación integral del estudiante, sino con la especialización en las materias básicas (matemáticas y lenguaje).

En cuanto a la forma de evaluar la calidad educativa en Chile, esta refleja que la educación entendida como la formación y el desarrollo de «todas y cada una de sus facultades y dimensiones» (Gervilla, 2000, p. 41) se simplifica en enseñar las materias básicas. Esta simplificación de la calidad educativa es perjudicial para el desarrollo de los estudiantes, porque se descuida la educación desde una visión de formación integral, tal como declara la Ley General de Educación (LGE) chilena n. ${ }^{\circ}$ 20.370: el objetivo de la educación está orientado a alcanzar «el desarrollo espiritual, ético, moral, afectivo, intelectual, artístico y físico, mediante la transmisión y el cultivo de valores, conocimientos y destrezas» (LGE, 2009, artículo 2. ${ }^{\circ}$ ). No obstante, al analizar esta definición declarativa de lo que se entiende por calidad en educación, con el Sistema de Medición de la Calidad de la Educación (SIMCE) se observa que el Estado se interesa solo por los resultados académicos en asignaturas básicas. Sin embargo, al hacer la medición en las asignaturas básicas de comprensión lectora, matemáticas y ciencias, la Organización para la Cooperación y el Desarrollo Económicos (OCDE) es categórica en señalar que los estudiantes chilenos obtienen resultados deficientes, puesto que ninguno de ellos es igual o mejor que el promedio de la OCDE en todas las mediciones (OECD, 2017). Lo señalado comprueba que no ha tenido efectos positivos aumentar las horas de matemáticas y lenguaje y disminuir las de historia, artes, música y educación física. Es decir, no se observan resultados académicos exitosos en las 
materias básicas, a las cuales se destinan la mayor parte de los esfuerzos y recursos, por ende, tampoco se ha logrado ningún éxito en la educación completa de los niños.

Además de lo planteado, en Chile se observa otra problemática que se relaciona con la visión occidental adoptada por los profesores chilenos que desvaloriza las culturas diferentes a la occidental eurocéntrica (Arias-Ortega, Quintriqueo y Valdebenito, 2018), en este caso se trata de la cosmovisión indígena presente en el país, y esto se denota principalmente en las regiones de Arica y Parinacota (AP) y en La Araucanía (LA), debido a que en la región de AP el $35,7 \%$ es indígena y de ese porcentaje un $75,3 \%$ es aimara, en la región de LA el 34,3\% de la población total es indígena, y el 97,8\% de los indígenas son mapuches (Instituto Nacional de Estadística [INE, 2018]).

Las cifras sobre la población de estas dos regiones de Chile presentan un escenario donde aproximadamente un tercio de la población se ve en problemas a la hora de aprender en las escuelas, debido a que no se contempla su idioma, su cosmovisión ni su episteme (Quilaqueo y Quintriqueo, 2017). Estas condiciones adversas para los estudiantes indígenas también se reflejan en el currículo escolar, debido a la invisibilización de la diversidad, puesto que se rige por una visión eurocéntrica de homogeneización y monoculturalización de la población (Quilaqueo y Quintriqueo, 2017; Quilaqueo et al., 2014).

En relación con la educación monocultural, los «estudios señalan la preeminencia de evaluación de contenidos curriculares sin considerar los contenidos de las culturas regionales del país, se excluye así a gran parte de la población indígena y persiste un currículum homogéneo, estático, organizado y estructurado» (Del Pino-Sepúlveda y Montanares-Vargas, 2019, p. 3), mientras que los pueblos indígenas fomentan conocimientos, estilos de enseñanzaaprendizaje y evaluaciones diferentes que con frecuencia se contraponen a los de la escuela (Treviño, 2006).

Producto de esta problemática se han estudiado las diferencias entre los resultados académicos obtenidos por estudiantes indígenas y no indígenas, buscando comprobar o discutir la problemática señalada (Blanco, 2017; Fernández y Hauri, 2016; McEwan y Trowbridge, 2007; Noe, Rodríguez y Zúñiga, 2005). Asimismo, hay investigaciones que tratan distintos factores que permiten predecir o relacionar variables en relación con los resultados académicos. Entre estas investigaciones se observan resultados disímiles. Por una parte, se señala que la situación económica familiar es el factor más determinante que condiciona los resultados académicos de los estudiantes (Mizala y Romaguera, 2000, 2001). Sin embargo, en la misma variable socioeconómica pero ahora específicamente midiendo las diferencias entre indígenas y no indígenas, la situación económica explica una pequeña parte de la brecha de resultados entre indígenas y no indígenas (McEwan y Trowbridge, 2007).

La evidencia más actualizada en relación con los factores que explican la brecha entre indígenas y no indígenas se encuentran en el documento de la United Nations Educational, Scientific and Cultural Organization (UNESCO). En los indicadores de inequidad de logros de aprendizaje de la 
UNESCO, entre los factores con mayor relevancia estadística destacan la repitencia escolar, el trabajo infantil, el alto nivel de escolaridad de la madre, la supervisión escolar de los padres, el tiempo de estudio en casa y la vulnerabilidad económica de las familias. En el último factor señalado los autores concluyen: «la diferencia estructural más relevante que se aprecia en la caracterización de los atributos personales y familiares de los estudiantes indígenas y no indígenas es la mayor vulnerabilidad social de los niños indígenas» (Valenzuela et al., 2017, p. 58).

El informe de la UNESCO (Valenzuela et al., 2017) tiene una gran relevancia debido a la cantidad de factores que analiza en cuanto a las diferencias entre indígenas y no indígenas. En este documento, además de analizar los factores internos de los estudiantes y las familias indígenas, se analizan los factores externos como la asistencia a establecimientos educacionales rurales; la matrícula en establecimientos privados urbanos; el nivel socioeconómico promedio de la escuela; la supervisión de estudio y de tareas en casa; el clima académico en la escuela; el clima del aula, y el ambiente laboral de los profesores. En todos los factores se detectaron diferencias perjudiciales para los indígenas en comparación con los no indígenas.

En la evidencia empírica sobre los resultados SIMCE de estudiantes indígenas mapuches, en contraste con estudiantes no mapuches, Fernández y Hauri (2016) señalan que «las niñas mapuche obtuvieron en promedio 25 puntos menos que sus pares no mapuche. En el caso de los niños mapuche y no mapuche la distancia es más significativa (27 puntos)» (p. 69).

Los antecedentes expuestos muestran dos variantes en la forma de analizar el problema de los bajos resultados académicos obtenidos por los estudiantes indígenas: 1) el problema surge en el instrumento de evaluación, en este caso el SIMCE, y 2) el problema surge desde la monoculturalidad de la enseñanza, que, además de monocultural, es diferente a la cultura y a las costumbres heredadas de sus ancestros. En este artículo se adscribe a la segunda forma de explicación del problema, debido a que se sostiene que un estudiante que comprende lo que se le enseña (sea indígena o no indígena) puede contestar de forma satisfactoria una prueba que mida los aprendizajes enseñados. Esta posición se amplía y se especifica en las conclusiones del presente artículo.

En relación con el problema planteado, el Gobierno de Chile ha desarrollado el programa de educación intercultural bilingüe (PEIB). Según lo declarado por el Estado, tiene por objeto mejorar la calidad educacional y contextualizar los contenidos curriculares para los estudiantes indígenas. Sin embargo, en la práctica, el PEIB se reduce a la creación de una asignatura de lengua indígena. Es importante señalar que este programa solo se imparte en escuelas que tengan más de un $20 \%$ de estudiantes indígenas y/o que voluntariamente deseen adscribirse al programa (PEIB, 2017).

Cabe señalar que existen múltiples variables que han sido estudiadas en distintos países sobre la temática de los resultados académicos (medidos por pruebas estandarizadas) de estudiantes que se desempeñan en contextos de diversidad social y cultural que, en pro de un trabajo con mayor rigor, no se 
han abordado en este artículo, pero que, sin embargo, es importante mencionar. Entre las variables estudiadas se encuentran el déficit en la formación de profesores para el reto de educar a estudiantes de diversas sociedades y culturas (Cernadas, Moledo y Santos, 2019); la sensibilidad intercultural y la satisfacción con la vida por parte de los estudiantes (Micó-Cebrián, Cava y Buelga, 2019); el rendimiento académico de estudiantes inmigrantes (Palavecino, 2017), y el diálogo interreligioso (Freixa-Niella et al., 2019), entre otros.

Desde la evidencia teórica y empírica, la hipótesis de esta investigación es que la condición étnica se relaciona con los resultados académicos, por ende, hay una relación significativa entre la cantidad de estudiantes indígenas de un establecimiento y el rendimiento académico en las pruebas de matemática y lenguaje SIMCE. Con el fin de comprobar la relación entre la condición indígena y los resultados académicos, se propone como objetivo determinar si existe relación entre ser indígena y los resultados en las pruebas de matemáticas y lenguaje SIMCE rendidas por niños de cuarto básico en las regiones de Arica y Parinacota y La Araucanía. Se han seleccionado estas dos regiones chilenas debido a que son las que concentran un porcentaje de población indígena mayor a un 30\% del total. La pregunta que busca responder este artículo es: ¿existe una relación entre el porcentaje de estudiantes indígenas matriculados en un establecimiento educacional y el rendimiento promedio de las escuelas en las pruebas SIMCE? Se opta por analizar esta variable debido a que en el informe de la UNESCO y en los antecedentes presentados no se encuentra la respuesta.

En relación con esta pregunta surgen los objetivos específicos que subyacen a esta investigación: 1) analizar la relación entre porcentaje de matrícula indígena por establecimiento, ruralidad, nivel económico promedio de los establecimientos y tipo de dependencia, con los resultados obtenidos en las pruebas de lenguaje y matemáticas, y 2) comparar los resultados en pruebas SIMCE de los establecimientos educacionales con alto porcentaje de estudiantes indígenas con los de bajo porcentaje de estudiantes indígenas.

\section{Método}

El presente estudio se rige por el paradigma positivista, es cuantitativo y ex post facto, debido a que los hechos o los datos se produjeron con anterioridad al estudio y no se han podido modificar o manipular (Bisquerra, 2009). Por ende, tiene un diseño no experimental transeccional, debido a que se realiza una observación "en un momento único en el tiempo" (Hernández, Fernández y Baptista, 2006, p. 226) y correlacional, al medir la relación entre dos o más variables (Bisquerra, 2009; Hernández et al., 2006).

\section{Contexto y muestra}

La región de Arica y Parinacota está ubicada en el extremo norte de Chile. Al norte limita con Perú; al sur, con la región chilena de Tarapacá; al este, con 
Bolivia, y al oeste, con el océano Pacífico. Cuenta con una población total de 226.058 habitantes, de estos 78.883 son indígenas, lo que equivale a un $35,7 \%$ de la población total regional, y el $75,3 \%$ son del pueblo aimara $(59.432$ personas). Del total de habitantes aimaras de la región, 8.332 o un $14 \%$ no cuentan con escolaridad formal o, dicho de otro modo, tienen 0 años de escolaridad en los sistemas públicos o privados de educación formal (Instituto Nacional de Estadística [INE], 2018).

La región de La Araucanía está ubicada en la zona centro-sur de Chile. Al norte limita con la región chilena del Biobío; al sur, con la región de Los Ríos; al este, con Argentina, y al oeste, con el océano Pacífico. Cuenta con una población total de 957.224 habitantes, de estos 321.328 pertenecen a un pueblo originario, lo que equivale a un 34,4\% del total, y el $97,8 \%$ de la población indígena es mapuche, con un total de 314.174 personas. Del total de habitantes mapuches en la región, 44.064 o un $14 \%$ no cuentan con escolaridad formal o, dicho de otra forma, tienen 0 años de escolaridad en los sistemas públicos o privados de educación formal, al igual que en la región de Arica y Parinacota.

La muestra está conformada por establecimientos educacionales cuyos estudiantes que cursaban el cuarto año de escolaridad básica del año 2018 fueran evaluados con las pruebas de lenguaje y matemáticas. Los criterios de exclusión fueron: 1) establecimientos educacionales que no rindieron en las pruebas SIMCE o sin registros oficiales de sus resultados, y 2) establecimientos que tuvieran una matrícula homogénea del $100 \%$ de estudiantes indígenas o no indígenas. En total, la muestra es de 741 establecimientos, 76 de la región de Arica y Parinacota, y 665 de La Araucanía. Se establecieron estas dos regiones chilenas debido a que son las que poseen un mayor porcentaje de habitantes indígenas a nivel nacional, lo que equivale a más de un tercio de la población total regional.

\section{Instrumento}

Para la obtención de datos, se solicitaron al Ministerio de Educación (MINEDUC) los resultados SIMCE del año 2018 correspondientes a las pruebas de lenguaje y matemáticas de cuarto año básico; datos que identifiquen la pertenencia a una sociedad indígena de los estudiantes chilenos; dependencia administrativa del establecimiento educacional (municipal, particular subvencionado, particular pagado); grupo socioeconómico promedio del establecimiento (bajo, medio-bajo, medio, medio-alto, alto), e identificación de localización del establecimiento (urbano o rural). La prueba SIMCE «es una evaluación de aprendizaje que aborda el logro de los contenidos y habilidades del currículo vigente [...] entregando información de los Estándares de Aprendizaje logrados por los estudiantes en los diferentes niveles de enseñanza» (Agencia de Calidad de la Educación, 2019, p. 1), su estructura es en base a preguntas de selección múltiple; cada pregunta tiene entre 3 y 4 alternativas de respuesta y solo una es correcta, y en la prueba de lenguaje hay preguntas 
que se responden escribiendo un texto (Agencia de Calidad de la Educación, 2019).

\section{Análisis de datos}

El análisis estadístico de los datos se realizó por medio del paquete estadístico SPSS v25 (IBM SPSS, 2016). En primer lugar, con la muestra $n=741$ escuelas, 76 de las cuales correspondían a las ubicadas en la región de Arica y Parinacota, y 665, a las ubicadas en la región de La Araucanía. Se calcularon los datos estadísticos descriptivos de la muestra (tabla 1).

Tabla 1. Datos descriptivos de la muestra

\begin{tabular}{lcccc}
\hline & Arica y Parinacota & \multicolumn{2}{c}{ La Araucanía } \\
\hline & Frecuencia & Porcentaje & Frecuencia & Porcentaje \\
\hline Grupo económico promedio del establecimiento & & & \\
\hline Bajo & 5 & 6,6 & 341 & 51,3 \\
\hline Medio-bajo & 31 & 40,8 & 226 & 34,0 \\
\hline Medio & 28 & 36,8 & 66 & 9,9 \\
\hline Medio-alto & 7 & 9,2 & 21 & 3,2 \\
\hline Alto & 4 & 5,3 & 11 & 1,7 \\
\hline Localización geográfica & & & & \\
\hline Urbano & 57 & 75,0 & 284 & 42,7 \\
\hline Rural & 19 & 25,0 & 381 & 57,3 \\
\hline Porcentaje de estudiantes indígenas por establecimiento & & \\
\hline $0 \%$ a 25\% & 44 & 57,9 & 192 & 28,9 \\
\hline $26 \%$ a 50\% & 18 & 23,7 & 165 & 24,8 \\
\hline $51 \%$ a 75\% & 10 & 13,2 & 138 & 20,8 \\
\hline $76 \%$ a 100\% & 4 & 5,3 & 170 & 25,6 \\
\hline Tipo de dependencia & & & & \\
\hline Municipal & 41 & 53,9 & 236 & 35,9 \\
\hline Particular subvencionado & 31 & 40,8 & 380 & 57,1 \\
\hline Particular pagado & 4 & 5,3 & 9 & 1,4 \\
\hline Servicio local de educación & - & - & 37 & 5,6 \\
\hline
\end{tabular}

Fuente: elaboración propia.

\section{Resultados}

En concordancia con el objetivo 1 planteado en esta investigación, se utilizaron las variables de ruralidad, nivel económico promedio de los establecimientos educacionales, porcentaje de matrícula indígena por establecimiento y tipo 
de dependencia para medir la correlación de cada una de ellas con los resultados en las pruebas SIMCE de lenguaje y matemáticas de las escuelas (tabla 2).

Tabla 2. Correlaciones

\begin{tabular}{lcccc}
\hline & Dependencia & $\begin{array}{c}\text { Nivel } \\
\text { económico } \\
\text { (escuela) }\end{array}$ & Ruralidad & $\begin{array}{c}\text { Estudiantes } \\
\text { indígenas }\end{array}$ \\
\hline Correlación región de Arica y Parinacota & & & \\
\hline Promedio lenguaje & $0,497^{* *}$ & $0,459^{* *}$ & $-0,291^{*}$ & $-0,300^{*}$ \\
\hline Promedio matemáticas & $0,444^{* *}$ & $0,407^{* *}$ & $-0,395^{* *}$ & $-0,333^{* *}$ \\
\hline Correlación región de La Araucanía & & & \\
\hline Promedio lenguaje & 0,063 & $0,349^{* *}$ & $-0,240^{* *}$ & $-0,227^{* *}$ \\
\hline Promedio matemáticas & 0,046 & $0,432^{* *}$ & $-0,380^{* *}$ & $-0,362^{* *}$ \\
\hline
\end{tabular}

** La correlación es significativa en el nivel $p<0,01$.

* La correlación es significativa en el nivel $p<0,05$

Fuente: elaboración propia.

El cálculo de las correlaciones señaladas para el caso de la región de Arica y Parinacota muestra que existe una correlación significativa entre el promedio de la prueba SIMCE de lenguaje y las variables tipo de dependencia $(r=0,497$, $p<0,01)$; nivel económico promedio de la escuela $(r=0,459, p<0,01)$; ruralidad $(r=-0,291, p<0,05)$, y porcentaje de estudiantes indígenas $(r=-0,300$, $p<0,05)$. En cuanto a la prueba SIMCE en matemáticas, las correlaciones significativas existieron con las variables dependencia $(r=0,444, p<0,01)$; nivel económico promedio de la escuela $(r=0,407, p<0,01)$; ruralidad $(r=$ $-0,395, p<0,01)$, y porcentaje de estudiantes indigenas $(r=-0,333, p<0,01)$.

Para el caso de la región de La Araucanía existe una correlación significativa entre el promedio de la prueba SIMCE de lenguaje y las variables nivel económico promedio de la escuela $(r=0,349, p<0,01)$; ruralidad $(r=-0,240$, $p<0,05)$, y porcentaje de estudiantes indigenas $(r=-0,227, p<0,01)$. En cuanto a la prueba SIMCE en matemáticas las correlaciones significativas existieron con las variables nivel económico promedio de la escuela $(r=0,432$, $p<0,01)$; ruralidad $(r=-0,380, p<0,01)$, y porcentaje de estudiantes indigenas $(r=-0,362, p<0,01)$.

\section{Regresiones lineales}

En concordancia con el objetivo 2 planteado en esta investigación, se realizó una regresión lineal simple que permite observar el promedio de cada establecimiento en las pruebas SIMCE de lenguaje y matemáticas, así como su relación con el porcentaje de estudiantes indígenas matriculados en cada establecimiento.

La regresión lineal efectuada para el caso de la región de Arica y Parinacota (tabla 3) muestra que el porcentaje de estudiantes indígenas por estableci- 
miento explica el 11,1\% del puntaje obtenido en la prueba SIMCE de matemáticas y el $9 \%$ del puntaje obtenido en la prueba SIMCE de lenguaje.

Tabla 3. Regresión lineal simple

\begin{tabular}{lcccc}
\hline Modelo & $\begin{array}{c}\text { Coeficientes no } \\
\text { estandarizados }\end{array}$ & $\begin{array}{c}\text { Coeficientes } \\
\text { estandarizados }\end{array}$ & $\mathbf{R}^{\mathbf{2}}$ & Sig. \\
\hline Regresión lineal SIMCE matemáticas & & & $0,000^{\star *}$ \\
\hline (constante) & 266,633 & & 0,111 & $0,005^{\star *}$ \\
\hline Estudiantes indígenas & $-0,518$ & $-0,333$ & \\
\hline Regresión lineal SIMCE lenguaje & & & $0,000^{\star *}$ \\
\hline (constante) & 280,155 & & & $0,011^{*}$ \\
\hline Estudiantes indígenas & $-0,413$ & $-0,300$ & 0,090 & 0 \\
\hline
\end{tabular}

Fuente: elaboración propia.

La regresión lineal efectuada para el caso de la región de La Araucanía (tabla 4) muestra que el porcentaje de estudiantes indígenas por establecimiento explica el 13,1\% del puntaje obtenido en la prueba SIMCE de matemáticas y un $5 \%$ del puntaje obtenido en la prueba SIMCE de lenguaje.

Tabla 4. Regresión lineal simple

\begin{tabular}{lcccc}
\hline \multicolumn{1}{c}{ Modelo } & $\begin{array}{c}\text { Coeficientes no } \\
\text { estandarizados }\end{array}$ & $\begin{array}{c}\text { Coeficientes } \\
\text { estandarizados }\end{array}$ & $\mathbf{R}^{\mathbf{2}}$ & Sig. \\
\hline $\begin{array}{l}\text { Regresión lineal SIMCE matemáticas } \\
\text { (constante) }\end{array}$ & 257,187 & & & $0,000^{* *}$ \\
\hline Estudiantes indígenas & $-0,390$ & $-0,362$ & 0,131 & $0,000^{* *}$ \\
\hline Regresión lineal SIMCE lenguaje & 270,730 & & & $0,000^{* *}$ \\
\hline (constante) & $-0,244$ & $-0,227$ & 0,050 & $0,000^{* *}$ \\
\hline
\end{tabular}

Fuente: elaboración propia.

En concordancia con el objetivo 2 planteado en esta investigación, se realizó una prueba $t$ de Student para muestras independientes, con el fin de efectuar una comparación de medias que permita observar los resultados (promedio) de los establecimientos educacionales con alto porcentaje de estudiantes indígenas $(\geq 50 \%)$ con los de bajo porcentaje de estudiantes indígenas $(\leq 50 \%)$ de la matrícula total.

Se realiza la prueba $t$ de Student puesto que se cumple con el supuesto de normalidad según la prueba aplicada de Kolmogorov-Smirnov $(p>0,05)$. Asimismo, se considera la homocedasticidad de varianzas con la prueba de igualdad de varianzas de Levene.

Los establecimientos educacionales en la región de La Araucanía con bajo porcentaje de estudiantes indígenas tienen resultados significativamente mayores 
en la prueba SIMCE de lenguaje $(\mathrm{M}=263,16, \mathrm{SE}=1,49)$ que los establecimientos educacionales con alto porcentaje de estudiantes indígenas $(M=253,63$, $\mathrm{SE}=1,91, t(661)=3,99, p<0.05, r=0,14)$. En la prueba SIMCE de matemáticas los establecimientos educacionales con bajo porcentaje de estudiantes indígenas obtienen un resultado significativamente mayor $(\mathrm{M}=246,3, \mathrm{SE}=$ 1,53) que los establecimientos educacionales con alto porcentaje de estudiantes indígenas $(\mathrm{M}=228,53, \mathrm{SE}=1,77, t(631)=7,62, p<0,05, r=0,22)$.

Para el caso de los establecimientos educacionales de la región de Arica y Parinacota no se encontraron diferencias significativas entre los establecimientos con bajo y alto porcentaje de estudiantes indígenas $(p>0,05)$

\section{Discusión y conclusión}

El promedio nacional en los resultados de las pruebas SIMCE en lenguaje es de 271 puntos, y en matemáticas, 260 puntos (SIMCE, 2018). En relación con esto, se constata que las dos regiones estudiadas tienen un puntaje menor al promedio nacional del SIMCE 2018 en las pruebas de lenguaje y matemáticas, incluso al seleccionar solo a los establecimientos que cuentan con menos de un $50 \%$ de estudiantes indígenas.

En los resultados de esta investigación se observa una brecha significativa entre establecimientos educacionales dependiendo de su porcentaje de estudiantes indígenas y no indígenas en Chile. Esta brecha también se observa en estudiantes indígenas y no indígenas de otros países de América Latina, como México (Blanco, 2019), Bolivia (McEwan, 2004), Argentina y Brasil (Paladino et al., 2016).

Los resultados obtenidos al correlacionar las variables de estudio con los resultados en las pruebas de lenguaje y matemáticas en las dos regiones consideradas se formulan para comprobar si existe relación entre ellas, no se pretende demostrar matemáticamente una causalidad.

Desde lo planteado en el párrafo anterior, la correlación realizada entre las variables en estudio confirman que el nivel económico promedio de los estudiantes que asisten a un establecimiento educacional se relaciona con los resultados en pruebas estandarizadas, coincidiendo con los resultados de Mizala y Romaguera $(2000,2001)$. Asimismo, otro factor que tiene una correlación significativa en la brecha en los resultados académicos es la ruralidad del establecimiento. Estos datos coinciden con los de Fernández y Hauri (2016), que muestran diferencias en los resultados obtenidos en las pruebas SIMCE tales como: los niños de escuelas rurales consiguen resultados SIMCE inferiores a los niños de escuelas urbanas, y la brecha se mantiene del año 2007 al 2014. Además, desde nuestros hallazgos (2019) podemos afirmar que hasta el presente esta brecha sigue existiendo.

En relación con la brecha analizada entre estudiantes indígenas y no indígenas, se constata que la condición indígena explica una parte de los resultados obtenidos en pruebas estandarizadas a diferencia de lo planteado por Noe et al. (2005). En su estudio concluye que «la condición étnica per se no es la varia- 
ble que explica la brecha observada entre los estudiantes indígenas y no indígenas en cuanto a rendimiento en la prueba SIMCE» (p. 27).

En concordancia con los resultados del informe de Hall y Patrinos (2005) para el Banco Mundial y los de esta investigación, podemos afirmar que los establecimientos con más estudiantes indígenas obtienen en promedio resultados académicos en pruebas estandarizadas más bajos que los que cuentan con menos estudiantes indígenas, por ende se mantiene esta situación por más de 13 años.

Los resultados del presente estudio muestran que para la región de Arica y Parinacota no hay diferencias significativas en los resultados de las pruebas SIMCE, en cambio, en la región de La Araucanía sí la hay. Estas diferencias han sido explicadas en diversos estudios que señalan a la colonización y a la posterior escolarización desde una episteme monocultural eurocéntrica como el origen de la mala calidad en la educación escolar (Mansilla et al., 2016; Olivé, 2009; Quilaqueo y Quintriqueo, 2017; Quilaqueo y Sartorello, 2018). Asimismo, la escuela no les enseña a los estudiantes indígenas lo que ellos necesitan aprender (Schmelkes, 2004). Desde estos planteamientos, la educación chilena en la Araucanía mantiene los principios de su fundación, que fueron: «combatir la barbarie del mapuche, civilizarlo y convertirlo en ciudadano» (Quilaqueo et al., 2014, p. 272).

La respuesta a la pregunta de investigación (¿Existe una relación entre el porcentaje de estudiantes indígenas matriculados en un establecimiento educacional y el rendimiento promedio de las escuelas en las pruebas SIMCE?), desde los resultados de la presente investigación, debemos decir que es sí. Los resultados obtenidos posibilitan comprender desde los datos cuantitativos las brechas existentes en el rendimiento académico entre indígenas y no indígenas, y explicar un porcentaje del problema de los resultados académicos en pruebas SIMCE. Prueba de ello es la relación negativa entre la cantidad de estudiantes indígenas de un establecimiento y el rendimiento en las pruebas SIMCE de lenguaje y matemáticas. Es decir, mientras más estudiantes indígenas tienen los establecimientos educacionales, más bajos son sus resultados en pruebas SIMCE. A esta aseveración fundada en los datos se adiciona una reflexión desde la teoría: esta realidad educativa para estudiantes indígenas se seguirá manteniendo si es que se sigue enseñando desde la lógica occidental monocultural. Cabe señalar que esta interpretación es una de las variadas que se podrían hacer.

Otra interpretación a estos resultados se puede dar en relación con un área política, con las falencias de los instrumentos ocupados en el SIMCE, de modo que, desde los planteamientos de Pino et al. (2016), el SIMCE se basa en la «noción de calidad orientada al mercado, reproductora de una sociedad neoliberal» (p. 337) y no considera los aprendizajes de los estudiantes en relación con su contexto. En esta misma línea, la brecha entre indígenas y no indígenas se mantendrá mientras exista el SIMCE, debido a que este sistema de evaluación «enmascara su función de legitimación y conservación del actual mercado escolar y de la segregación social que produce» (Acuña, Mendoza y Rozas, 2019, p. 64). 
La crítica presentada en este artículo se enfoca hacia cómo se enseñan los contenidos a los estudiantes indígenas y no hacia el sistema de evaluación en sí, debido a que se entiende y se acepta que los entes gubernamentales nacionales e internacionales necesitan medir los logros de aprendizaje con pruebas estandarizadas. En concordancia con lo señalado, se puede observar que, desde el punto de vista internacional y en los niveles más altos de las pruebas PISA, hay países con culturas y formas de aprender muy disímiles, por ejemplo: los primeros lugares a nivel mundial se encuentran en países de Asía, América del Norte, Oceanía y norte de Europa (Schleicher, 2019). Aquellos países poseen culturas y métodos de enseñanza diferentes, pero con resultados de logro académico similares. Asimismo, en los primeros lugares se encuentran países con sociedades indígenas numerosas, activas y vigentes, como en el caso de Canadá y Nueva Zelanda. Por los motivos señalados, en este artículo se hace una crítica a la forma de enseñar y no al sistema de evaluación estandarizado, puesto que un estudiante que comprende lo enseñado puede explicar lo aprendido y, por ende, aumenta sus posibilidades de contestar de forma certera las preguntas de pruebas estandarizadas como el SIMCE o PISA. Por consiguiente, si la forma de enseñar los contenidos a los estudiantes indígenas sigue siendo desde una episteme ajena a ellos, las futuras evaluaciones estandarizadas seguirán mostrando las mismas brechas.

En el ámbito local chileno y actual, los datos obtenidos del análisis de las dos regiones con mayor porcentaje de población indígena es un insumo más que se debe tener en cuenta para la toma de decisiones en Chile, más ahora que el país está pasando por un momento en el que la sociedad civil está exigiendo cambios estructurales en las políticas públicas (Atria, 2020), cambios que se expresan en la petición del cambio de la Constitución política del país. Específicamente, en educación, los resultados de esta investigación permiten ver con claridad la brecha existente hoy en día entre los alumnos indígenas y los no indígenas.

En relación con la labor de los docentes que se desempeñan en establecimientos educacionales con estudiantes indígenas, es conveniente que incorporen elementos propios de las culturas de sus estudiantes y no solo enseñen desde una episteme monocultural como el currículo nacional de educación, que es uno y para todos, un currículo que no contempla la episteme de las diversas sociedades indígenas que viven en Chile.

En cuanto a las investigaciones futuras en relación con los factores que condicionan los resultados en las pruebas SIMCE, se sugiere buscar respuestas desde metodologías cualitativas e indagar en los factores percibidos por los estudiantes, los profesores, los padres y las madres de familias. Asimismo, al ser una temática con múltiples factores, se sugiere estudiar los resultados SIMCE focalizados y específicos, en un número reducido de factores acotado a la especialidad del investigador, puesto que los resultados académicos tienen influencia desde la sociología, la psicología, la economía, la filosofía y la medicina, entre otras.

Desde los resultados de este artículo más los datos precedentes se concluye que, los establecimientos educacionales que tienen una alta concentración de estudiantes indígenas obtienen resultados académicos más bajos que los esta- 
blecimientos con menos concentración de estudiantes indígenas. Se debe considerar esta conclusión como la afirmación de uno de los múltiples factores condicionantes de las brechas educativas entre estudiantes que se analizan en contextos de diversidad social y cultural.

\section{Referencias bibliográficas}

Acuña, F.; Mendoza, M. y Rozas, T. (2019). El hechizo del SIMCE. Revista Chilena de Pedagogia, 1(1), 54-70. Recuperado de <https://revistas.uchile.cl/index.php/ $\mathrm{RCHP} /$ article/download/55633/58588/>.

Agencia de Calidad de la Educación (2019). ¿Qué es el SIMCE? Santiago de Chile. Recuperado de $<$ https://www.agenciaeducacion.cl/evaluaciones/que-es-el-simce/ nacionales/ $>$.

Arias-Ortega, K.; Quintriqueo, S. y Valdebenito, Z.V. (2018). Monoculturalidad en las prácticas pedagógicas en la formación inicial docente en La Araucanía, Chile. Educação e Pesquisa, 44, 1-19. $<$ https://doi.org/10.1590/s1678-4634201711164545>

Atria, F. (2020). Constituent Moment, Constituted Powers in Chile. Law and Critique, 31(1), 51-58. $<$ https://doi.org/10.1007/s10978-020-09258-8>

Bisquerra, R. (2009). Metodología de la investigación educativa. Madrid: La Muralla.

Blanco, E. (2017). Los alumnos indígenas en México: Siete hipótesis sobre el rezago en los aprendizajes de nivel primario. REICE: Revista Iberoamericana sobre Calidad, Eficacia y Cambio en Educación, 15(3), 81-112. <https://doi.org/10.15366/reice2017.15.3.005>

- (2019). Análisis de la brecha de aprendizaje entre indígenas y no indígenas en la enseñanza primaria en México. Revista Electrónica de Investigación Educativa, 21(1), 1-15. <https://doi.org/10.24320/redie.2019.21.e16.1941>

BRAVO, J. (2011). SIMCE: Pasado, presente y futuro del sistema nacional de evaluación. Estudios públicos, 123, 189-211. Recuperado de <https://www.cepchile.cl/ cep/estudios-publicos/n-121-a-la-150/estudios-publicos-n-123-2011/simce-pasadopresente-y-futuro-del-sistema-nacional-de-evaluacion>.

Cernadas, F.X.; Moledo, M.L. y Santos, M. (2019). Diversidad cultural y escenarios migratorios: Un estudio sobre formación de profesores. Educar, 55(1), 19-37. <https://doi.org/10.5565/rev/educar.961>

Eyzaguirre, B. y Fontaine, L. (1999). ¿Qué mide realmente el SIMCE? Estudios Públicos, 75, 107-161.

Fernández, M.C. y Hauri, S. (2016). Resultados de aprendizaje en La Araucanía: La brecha de género en el Simce y el androcentrismo en el discurso de docentes de lenguaje y matemática. Calidad en la Educación, 45, 54-89. <https://doi.org/10.4067/S0718-45652016000200003>

Freixa-Niella, M.; Rubio-Hurtado, M. J.; Sánchez-Martí, A. y Vilà-Baños, R. (2019). La educación del siglo xxi ante el diálogo interreligioso. Educar, 55(1), 101-117. $<$ https://doi.org/10.5565/rev/educar.973>

Gervilla, E. (2000). Un modelo axiológico de educación integral. Revista Española de Pedagogía, 58(215), 39-57. Recuperado de <www.jstor.org/stable/23765286>. 
Hall, G. y Patrinos, H.A. (2005). Pueblos indigenas, pobreza y desarrollo humano en América Latina: 1994-2004. Washington DC: Banco Mundial.

Hernández, R.; Fernández, C. y Baptista, P. (2006). Metodología de la investigación. Vol. 4. México DF: McGraw-Hill Interamericana.

Instituto Nacional de Estadísticas (INE) (2018). Síntesis de resultados Censo 2017. Santiago de Chile. Recuperado de <https://www.censo2017.cl/descargas/ home/sintesis-de-resultados-censo2017.pdf>.

Mansilla, J.; Llancavil, D.; Mieres, M. y Montanares, E. (2016). Instalación de la escuela monocultural en La Araucanía, 1883-1910: Dispositivos de poder y Sociedad Mapuche. Educação e Pesquisa, 42(1), 213-228. <https://doi.org/10.1590/S1517-9702201603140562>

McEwan, P.J. (2004). La brecha de puntajes obtenidos en las pruebas por los niños indígenas en Sudamérica. En Etnicidad, raza, género y educación en América Latina (pp. 283-313). Santiago: PREAL.

McEwan, P.J. y Trowbridge, M. (2007). The achievement of indigenous students in Guatemalan primary schools. International Journal of Educational Development, 27(1), 61-76. <https://doi.org/10.1016/j.ijedudev.2006.05.004>

Meckes, L. y Carrasco, R. (2010). Two decades of SIMCE: An overview of the National Assessment System in Chile. Assessment in Education: Principles, Policy y Practice, 17(2), 233-248. <https://doi.org/10.1080/09695941003696214>

Mella, O. y Ortiz, I. (1999). Rendimiento escolar: Influencias diferenciales de factores externos e internos. Revista Latinoamericana de Estudios Educativos, 29(1), 69-92.

Micó-Cebrián, P.; Cava, M.-J. y Buelga, S. (2019). Sensibilidad intercultural y satisfacción con la vida en alumnado autóctono e inmigrante. Educar, 55(1), 39-57. <https://doi.org/10.5565/rev/educar.965>

Miranda, J. (2013). Factores que obstaculizan el cambio en profesores y directivos de liceos vulnerables en la región de la Araucanía (Chile). Educar, 49(2), 183206. <https://doi.org/10.5565/rev/educar.416>

Mizala, A. y Romaguera, P. (2000). Determinación de factores explicativos de los resultados escolares en educación media en Chile. Documentos de Trabajo, 85. Recuperado de <https://ideas.repec.org/p/edj/ceauch/85.html>.

- (2001). Factores socioeconómicos explicativos de los resultados escolares en la educación secundaria en Chile. El Trimestre Económico, 68(4), 272, 515-549.

Noe, D.; Rodríguez, J. y ZúñIgA, I. (2005). Brecha étnica e influencia de los pares en el rendimiento escolar: Evidencia para Chile. Santiago de Chile: Naciones Unidas. Serie Políticas Sociales, 102. Recuperado de <https://www.cepal.org/mujer/noticias/ noticias/9/26089/Serie102.pdf>.

OECD (2017). PISA 2015. Assessment and Analytical Framework: Science, Reading, Mathematic, Financial Literacy and Collaborative Problem Solving, revised edition, PISA. Paris: OECD Publishing. <http://dx.doi.org/10.1787/9789264281820-en>

Olıvé, L. (2009). Por una auténtica interculturalidad basada en el reconocimiento de la pluralidad epistemológica. En Pluralismo epistemológico (pp. 19-30). La Paz: CLACSO, CIDES-Universidad Mayor de San Andrés. 
Paladino, M.; Ossola, M.M.; Castro Freitas, A.E. de y Rosso, L.C. (2016). Pueblos indígenas y Educación Superior: Indagaciones y experiencias en Argentina y Brasil. Revista del Instituto de Investigaciones en Educación, 1-21.

Palavecino, C. (2017). El éxito escolar en matemáticas de los estudiantes peruanos inmigrantes: Estudios de casos en un contexto vulnerable. Alcalá de Henares: Universidad de Alcalá. Recuperado de <http://hdl.handle.net/10017/38168>.

PEIB (2017). Programa de Educación Intercultural Bilingüe (PEIB). 1. ${ }^{\mathrm{a}}$ ed. Santiago de Chile. Recuperado de <http://peib.mineduc.cl/wp-content/uploads/2018/05/ 20180226-PEIB-2010-2016-Versión-Final.pdf>.

Pino, M.; Oyarzún, G. y Salinas, I. (2016). Crítica a la rendición de cuentas: Narrativa de resistencia al sistema de evaluación en Chile. Cad. Cedes Campinas, 36(100), 337-354.

Pino-Sepúlveda, M. del y Montanares-Vargas, E. (2019). Evaluación comunicativa y selección de contenidos en contextos escolares vulnerables chilenos. Revista Electrónica de Investigación Educativa, 21(1), 1-12. <https://doi.org/10.24320/redie.2019.21.e03.1984>

Quilaqueo, D. y Quintriqueo, S. (2017). Métodos educativos mapuche: Retos de la doble racionalidad educativa: Aportes para un enfoque de educación intercultural. $1 .^{\mathrm{a}}$ ed. Temuco: Universidad Católica de Temuco.

Quilaqueo, D.; Quintriqueo, S.; Torres, H. y Muñoz, G. (2014). Saberes educativos mapuches: Aportes epistémicos para un enfoque de educación intercultural. Chungará (Arica), 46(2), 271-284. <https://doi.org/10.4067/S0717-73562014000200008>

Quilaqueo, D. y Sartorello, S. (2018). Retos epistemológicos de la interculturalidad en contexto indígena. Alpha: Revista de Artes, Letras y Filosofia, 0(47), 47-61. <https://doi.org/10.32735/S0718-220120180004700163>

SAlazar, G. (2009). Bicentenario urbano en Chile: ¿Qué pueblo para qué ciudad? Revista INVI, 24(67), 9-18. <https://doi.org/10.4067/S0718-83582009000300001>

SchleIcher, A. (2019). PISA 2018: Insights and Interpretations. OECD Publishing.

Schmelkes, S. (2004). La Educación Intercultural: Un Campo en Proceso de Consolidación. Revista Mexicana de Investigación Educativa, 9(20), 9-13.

Treviño, E. (2006). Evaluación del aprendizaje de los estudiantes indígenas en América Latina: Desafíos de medición e interpretación en contextos de diversidad cultural y desigualdad social. Revista Mexicana de Investigación Educativa, 11(28), 225-268.

Tyler, R.W. (2013). Basic principles of curriculum and instruction. 3. ${ }^{\mathrm{a}}$ ed. Chicago: The University of Chicago Press.

Valenzuela, J.P.; Allende, C.; Fuenzalida, D. y Villalobos, C. (2017). Inequidad en los logros de aprendizaje entre los estudiantes indígenas de América Latina: ¿Qué nos dice TERCE? Santiago de Chile: Unesco / Oficina Regional de Educación para América Latina y el Caribe. Recuperado de <https:/unesdoc.unesco.org/ ark:/48223/pf0000260858.locale $=$ es $>$. 